\title{
Seizures After Overdoses of Bupropion Intake
}

\author{
Hasan Kara, Ahmet Ak, Ayşegül Bayır, Demet Acar, Rabia İstanbulluoğlu, Selim Değirmenci \\ Department of Emergency Medicine, Selçuk University Selçuklu Faculty of Medicine, Konya, Turkey
}

\section{ABSTRACT}

Background: Bupropion is a new-generation monocyclic antidepressant that has been accidentally found to have potential effects on reducing nicotine addiction. It is structurally similar to stimulants such as amphetamine and inhibits dopamine and noradrenalin reuptake selectively.

Case Reports: We report two cases with no history of epilepsy who took oral bupropion for depression and had generalised tonic-clonic type of seizures in their follow-ups.

Conclusion: After an overdose of bupropion, clinical effects are seen primarily on the neurological, cardiovascular, and gastrointestinal systems. Neurological effects can include tremor, confusion, agitation, hallucinations, coma, and seizures.

Key Words: Bupropion, overdoses, seizures

Received: 21.04.2012

Accepted: 25.09.2012

\section{Introduction}

Today, bupropion is an antidepressant that is increasingly used in depression and smoking cessation. The increased use has brought about seizures and thus, clinicians have had to revise their knowledge on the effects of this drug. Standard approaches applied depending on the type and time of poisoning are similar in emergency services. In contrast to other commonly used antidepressants, bupropion leads to less weight gain and sexual dysfunction. Bupropion has a different chemical structure to selective serotonin reuptake inhibitors, cyclic antidepressants, and other agents typically used in depression treatment. Its chemical structure is similar to dietylpropion, an anorexiant, and sympathomimetic amine, which was developed to be used in intermittent or short-period obesity treatment (1). Although the mechanism of the effect of bupropion has not been completely elucidated, the drug and its metabolites have a weak inhibitor effect on noradrenalin and dopamine reuptake. However, it has no effect on serotonin reuptake (2). Bupropion's sympathomimetic amine structure suggests that it may act via catecholamine release in the central nervous system and may possibly lead to hypothalamic stimulation. This mechanism may be partially responsible for the seizures seen in cases of bupropion overdose. Seizures of all forms can occur both with treatment doses and overdose. Seizures seen in the adult population in cases of bupropion overdoses constitute a well-defined risk. However, seizures in children are not common (3). Today, immediate release (IR), sustained release (SR) and extended release $(\mathrm{XL})$ forms of bupropion are available on the market under the brands Wellbutrin and Zyban.

\section{Case Reports}

\section{Case 1}

A 19-year-old female patient who took 30 pills of $150 \mathrm{mg} \mathrm{bu-}$ propion (Wellbutrin) XL, prescribed to her a fortnight ago for depression, was immediately brought to emergency services. The patient, whose general medical condition was good, was conscious and adequately cooperative. She had stable vital signs with a Glasgow Coma Score (GCS) of 15 points, and had two tonic-clonic type of seizures that lasted 5-10 seconds, with a few minutes in between, 6 hours after her hospitalisation. Convulsive seizures were intervened with intravenous Diazem (10 mg) and no additive antiepileptic treatment was administered. In the analysis of the patient, no condition that could cause seizures was determined. The patient had no problems in the follow-up and was discharged on the third day of her hospitalisation.

\section{Case 2}

A 20-year-old female patient who had no previous ailment or history of drug use was taken to emergency services 5 to 6 hours after she had taken 15 tablets of $150 \mathrm{mg}$ Wellbutrin $\mathrm{XL}$, which was used by her mother. The patient, whose general medical condition was good and who was conscious and adequately cooperative, had stable vital signs with a GCS of 15 points. She had a generalised tonic-clonic seizure for $30 \mathrm{sec}-$ onds just after her hospitalisation. The convulsive seizure was intervened with intravenous Diazem ( $5 \mathrm{mg}$ ) and no additional antiepileptic treatment was administered. In the analysis of the patient, no condition which could cause seizures was determined. The patient had no problems in the follow-up and was discharged on the third day of her hospitalisation.

\section{Discussion}

Today, the increase in psychiatric problems has reached a very significant level. This incidence has become a problem on both an individual and public health level. Poisoning cases require serious handling and generally respond positively to the treatment applied. It has been determined that $6.1 \%$ of new- 
onset seizures are linked to drugs (4). Studies have reported that $9 \%$ of status epilepticus cases admitted to the emergency services is caused by drug toxicity, drug use for pleasure, and excessive dose $(5,6)$.

Bupropion is a new-generation monocyclic antidepressant whose potential effect on reducing nicotine addiction was accidentally found. It significantly prolongs smoking intervals and was licensed with this aim (7). Unlike other antidepressants on the market, bupropion has a monocyclic aminoketone structure. It is well absorbed in the gastrointestinal system and is metabolised in the liver. The half-life of bupropion is 12 hours; it is excreted in urine (1).

New-generation antidepressants used in the treatment of depression are generally well tolerated. However, almost all antidepressants have the potential to lead to seizure (8). Compared with previous years, while the number of seizures related to tricyclic antidepressants, cocaine, and theophylline has declined, the cases of seizures caused by new drugs containing tramadol, venlafaxine, and especially bupropion have increased (9). Our patients were admitted to hospitals just after drug intake but generalised seizures occurred after 12 hours.

Active metabolites of bupropion result from intensive liver metabolism of $(R, R)$-hydroxybupropion, $(S, S)$-hydroxybupropion, threo-hydrobupropion and erythro-hydrobupropion. The mechanism of action is thought to depend on weak noradrenalin and dopamine reuptake inhibition (10). Bupropion has sudden, continuous, and prolonged cyclothymic forms. In sudden and continuous cyclothymic forms, peak plasma levels are seen within about 2 and 3 hours, respectively (1). After an overdose of bupropion, clinical effects are primarily on the neurological, cardiovascular and gastrointestinal systems. Neurological effects can include tremor, confusion, agitation, hallucination, coma, and seizures. Cardiovascular effects involve tachycardia and conduction defects. QRS and QT prolongation can be seen. Gastrointestinal effects include trichinosis and vomiting. Mortalities have been reported but are not common $(3,11)$.

Seizures can emerge both with treatment doses and an overdose of bupropion. They can be caused by all forms of bupropion available on the market. In therapeutic use of the SR form, the risk of seizure is about $0.1 \%$ if the dose is no more than $300 \mathrm{mg} /$ day. It has been reported that the incidence of seizures caused by overdose intake makes up a third of the cases with the IR form (12). A study has suggested that there is a close relationship between seizures and dose. Those who take more than 30 tablets are more prone to seizures and almost every patient who takes more than 60 tablets has seizures (13). In electrocardiograms of our cases, no dysrhythmia or conductive defects were detected. For most of our patients who suffered from seizures, benzodiazepine was used as a treatment regime. The main pillar of treatment in case of bupropion overdose is supportive care. If patients come to the hospital just after the drug is taken, active carbon can be given. In our cases, supportive care was started right after admission and the patients were only given benzodiazepine during seizure. We did not measure serum bupropion concentration in our patients. While serum bupropion concentration measurement could be used as an academic means to confirm intake, laboratory tests are rarely completed on the same day and the result does not affect the patient's treatment and discharge. Our patients suffered from seizures after each had taken $4.5 \mathrm{~g}$ and $9 \mathrm{~g}$ of the $\mathrm{XL}$ form of bupropion. Our case study suggests that there is a relationship between dose and seizures. It has been established that patients who take more than 15 tablets are more vulnerable to seizures. Consistent with this, both of our patients experienced seizures.

In conclusion, Bupropion, a drug launched to treat depression and smoking cessation, can cause seizures in patients who do not previous history of convulsion. Our study emphasises the importance of determining the potential risk of a drug for suicidal poisoning before it is presented to the market. Therefore, clinicians should consider that bupropion may have convulsive effects even at lower doses.

\section{Ethics Committee Approval: N/A.}

Informed Consent: Written informed consent was obtained from patients.

Peer-review: Externally peer-reviewed.

Author contributions: Concept - H.K., A.B.; Design - H.K., A.A., S.D.; Supervision - D.A., R.I.; Resource - R.I., S.D.; Materials - D.A., R.I.; Data Collection\&/or Processing - H.K., A.B., S.D.; Analysis\&/or Interpretation - H.K., A.A., D.A.; Literature Search - H.K., R.I., S.D.; Writing - H.K., A.B. ; Critical Reviews - A.A., A.B.

Conflict of Interest: No conflict of interest was declared by the authors. Financial Disclosure: No financial disclosure was declared by the authors.

\section{References}

1. Spiller HA, Schaeffer SE. Multiple seizures after bupropion overdose in a small child. Pediatr Emerg Care 2008;24:474-5. [CrossRef]

2. Gobbi G, Slater S, Boucher N, Debonnel G, Blier P. Neurochemical and psychotropic effects of bupropion in healthy male subjects. J Clin Psychopharmacol 2003;23:233-9. [CrossRef]

3. Biswas AK, Zabrocki LA, Mayes KL, Morris-Kukoshi CL. Cardiotoxicity associated with intentional ziprasidone and bupropion overdose. J Toxicol Clin Toxicol 2003;41:79-82. [CrossRef]

4. Pesola GR, Avarsarala J. Bupropion seizure proportion among newonset generalized seizures and drug related seizures presenting to an emergency department. J Emerg Med 2002;22:235-9. [CrossRef]

5. Lowenstein DH, Alldredge BK. Status epilepticus at an urban public hospital in the 1980s. Neurology 1993;43:483-8. [CrossRef]

6. Alldredge BK, Lowenstein DH, Simon RP. Seizures associated with recreational drug abuse. Neurology 1989;39:1037-9. [CrossRef]

7. Britton J, Jarvis MJ. Bupropion:a new treatment for smokers. Nicotine replacement treatment should also be available on the NHS. BMJ 2000;321:65-6. [CrossRef]

8. Montgomery SA. Antidepressants and seizures:emphasis on newer agents and clinical implications. Int J Clin Pract 2005;59:1435-40. [CrossRef]

9. Thundiyil JG, Kearney TE, Olson KR. Evolving epidemiology of drug-induced seizures reported to a Poison Control Center System. J Med Toxicol 2007;3:15-9. [CrossRef]

10. Stahl SM, Pradko JF, Haight BR, Modell JG, Rockett CB, LearnedCoughlin S. A Review of the Neuropharmacology of Bupropion, a Dual Norepinephrine and Dopamine Reuptake Inhibitor. Prim Care Companion J Clin Psychiatry 2004;6:159-66. [CrossRef]

11. Rohrig TP, Ray NG. Tissue distribution of bupropion in fatal overdose. J Anal Toxicol 1992;16:343-5. [CrossRef]

12. Starr P, Klein-Schwartz W, Spiller H, Kem P, Ekleberry SE, Kunkel S. Incidence and onset of delayed seizures after overdoses of extended-release bupropion. Am J Emerg Med 2009;27:911-5. [CrossRef]

13. Balit CR, Lynch CN, Isbister GK. Bupropion poisoning:a case series. Med J Aust 2003;178:61-3. 